\title{
Communication and Strategy: the Inner Conflict of Teacher's Discourse
}

\author{
Tao Jiang \\ Graduate School of Education, Peking University, Haidian, Beijing, China
}

\begin{abstract}
Teachers' discourse includes two parts: student-centered discourse and teacher-centered discourse. Both of them have communicative and strategic dimensions which cause the inner conflict of teachers' discourse. This conflict originates from the different natures of education, teleological nature and non-teleological nature, and distinguished natures of teaching as a profession, i.e. normative and non-normative natures.
\end{abstract}

Keywords - teachers' discourse, communicative dimension, strategic dimension

\section{交往性与策略性：教师话语的内在冲突*}

\author{
江 涛 \\ 北京大学教育学院, 海淀, 北京, 中国
}

\begin{abstract}
摘 要 教师话语可分为 “以学生为中心的话语” 和 “以教师为中心的话语”, 两类教师话语中都兼具 “交往性” 和 “策略性”, 这构成了教师话语的内在冲突。这种冲突根源于教育的 “目的性”与 “非目的性” 以及教师职业的 “规范性” 与 “非规范性”。
\end{abstract}

关键词＼cjkstart教师话语，交往性，策略性

话语（discourse）对于教师具有显而易见的重要性, 因而话语分析是理解教师的可能的和必需的途径。“话语” 一词的含义纷繁复杂, 本文中 “话语” 与费尔克拉夫在《话 语与社会变迁》中的用法相同: “我在比较窄的意义上使用 “话语”一词, 即用它来指称口头语言或书面语言的使用。 在语言学家传统上就 “语言使用”、“言语” (parole) 或 ‘语 言表现' (performance) 进行写作的地方, 我将使用 “话语” 一词”。(费尔克拉夫，2003：58）“在使用 “话语”一词时, 我的意图是把语言使用当作社会实践的一种形式, 而不是 一个纯粹的个体行为或情境变量的一个折射。……话语既 是一种表现形式, 也是一个行为形式, 一一以这种形式, 人们有可能对这个世界产生作用, 特别是与这个世界彼此 产生作用”。(费尔克拉夫，2003：59）本文视 “文本” 为 “话语”的一种形式。

教师话语是个庞杂的体系, 不妨按照 “话语对象” 对 其进行基本的分类。福柯在《知识考古学》中特别提出了 四种考察话语 (形态) 的角度, 其中之一便是 “话语对象”, 早在《巅狂与文明》中, 福柯就从话语对象的角度分析了 古典时代的精神病学是如何建立一个详细说明对象的基本
框架的, 这种框架是话语对象出现的必要条件。(李猛, 1999: 381)

如果以 “话语对象” 为标准, 那么教师话语主要包括 两类: “以学生为中心的话语” 和 “以教师为中心的话语”。 “以学生为中心的话语” 以学生为话语对象, 包括 “教学 性话语” 和 “教育性话语”。前者包括授课与备课中的话语, 备课中的话语主要包括教案、学案以及教学材料的编制等; 后者主要指教师为影响学生道德和人格发展而运用的话 语, 比如批评表扬、心理辅导、书写评语等。“以教师为中 心的话语” 包括学校的教师考评中的话语和教师研修中的 话语, 教师考评中的话语主要包括学年总结、职称评定、 表彰大会等活动中的话语, 教师研修中的话语包括教师培 训、校本研修、读书、科研及论文写作等活动中的话语。

“以学生为中心的话语” 是教师话语的基本类型, 当 教师职业产生之时, 教师话语便天然的是以学生为中心的, 因为 “教师” 的存在是以 “学生” 的存在为前提的, 但是 随着教师发展的日趋重要, “以教师为中心的话语” 在学校 中占据日益重要的地位, 或者说, “教师” 作为一个重要的 
话语对象被创造了出来。1

现有的关于教师话语的研究大多是针对以学生为中心 的教师话语, 尤其集中在教师的课堂话语。( 牛海彬, 2010:8-17）对于 “以教师为中心的话语” 的研究却很少。 本文将对两类教师话语做一整体性透视：1. 运用哈贝马斯 的 “语言互动的纯粹类型 (pure types of linguistically mediated interaction)” 框架, 论证教师话语中同时存在 “交 往性” 和 “策略性”; 2. 从 “互文性” 的角度说明教师话语 的 “交往性” 和 “策略性” 是交织在一起, 难以剥离的; 3. 进一步指出教师话语的 “交往性” 和 “策略性” 的冲突 源于 “教育” 和 “教师” 的特性。

\section{1. 教师话语的内在冲突: “交往性”与 “策略性”}

哈贝马斯认为, 现代性导致语言的 “交往性” (communicative) 使用（它旨在获取理解）被语言的 “策 略性”（strategic）使用（它旨在获取成功）所置换。（哈贝 马斯, 2004[1983-1987]）哈贝马斯的这种区分与对 “以言 行事” 和 “以言取效” 的区分相对应, “在一些言语行为中 所有的参与者追求的是以言行事的目的, 而且只追求以言 行事的目的, 我把这些言语行为称为交往行为; 另一方面, 在一些言语行为中至少有一方的参与者试图通过他的言语 行为对对方造成以言取效的后果, 我把这些言语行为视为 策略行为”。(哈贝马斯，2004[1983-1987]: 281)

哈贝马斯进一步将交往行为分为三种纯粹类型: 会话、 规范行为和戏剧行为 (哈贝马斯, 2004[1983-1987]: 303-311), 这样就将语言互动划分为四大类型, 建构了 “语 言互动的纯粹类型” 框架 (哈贝马斯, 2004[1983-1987]: 312):

\begin{tabular}{|c|c|c|c|c|c|c|}
\hline 行为类型 & 典型的言语行为 & 语言功能 & 行为取向 & 基本立场 & 有效性要求 & 世界关联 \\
\hline 策略行为 & 以言表意 行为命令式 & 影响对方 & 以目的为取向 & 客观立场 & 现实性 & 客观世界 \\
\hline 会话行为 & 记述式 & 呈现事态 & 以沟通为取向 & 客观立场 & 真实性 & 客观世界 \\
\hline 规范立场 & 调节式 & 建立人际关系 & 以沟通为取向 & 规范立场 & 正确性 & 社会世界 \\
\hline 戏剧行为 & 表现式 & 自我表现 & 以沟通为取向 & 表现立场 & 真诚性 & 主观世界 \\
\hline
\end{tabular}

我们可以利用这一框架对教师话语进行分析。“交往 性” 和 “策略性” 同时体现在教师的话语中, 并在两类教 师话语中都有体现, 它们构成了教师话语的基本冲突。在 “以学生为中心的话语” 中, 课堂互动一一尤其是自然科 学学科知识点教学——是典型的会话行为; 班主任在学生 工作中常常持一种规范立场, 比如在调解学生矛盾时; 教 师站在讲台上, 将自身的行为和语言艺术化, 比如表现出

“本文 “教师” 是指 “中国中小学教师”。

${ }^{1}$ 在文明的开端, 教师便在实践领域出现了, 但是直到今天, “教 师” 在话语和知识领域才真正诞生, 它突出表现在 “教师经验” 变为了 “教师知识”, “教研” 变为了 “科研”, 面向学生的 “实践” 与面向自身的 “反思” 提到了同等的地位。教师教育不仅成为更 大规模的社会实践, 而且成为专门的学科领域和知识领域。教师 个体不再仅仅面对学生, 而将眼光转向自身; 教师群体乃至教育 研究者群体将 “教师” 视为谈论、研究的对象。“教师” 何以会成 为知识的主体，生产关于自身实践的知识? “教师” 何以成为知 识的客体, 成为被言说的对象? 这些福柯式的问题很值得研究。
自己幽默的语言、洣博的知识和宽容的心态时, 可视为一 种戏剧行为。另一方面, 上述三种话语也都可以是一种 “策 略行为”, 比如, 无论是课堂互动、还是班主任学生工作乃 至教师的自我展示, 都可能采用命令式行为。

更为重要的是，哈贝马斯对语言互动的分类是一种“纯 粹类型”, 现实的教师话语的 “交往性” 和 “策略性” 往往 是交织在一起的。比如, 班主任为了鼓励一名不太被班级 所接纳后进生, 而表扬他的一个与其他同学相比并不突出 的优点。这是一个策略行为, 因为意在影响这名同学和其 他同学。但班主任表扬的具体事实是真实的, 也持有一种 正确的规范立场, 希望改善学生之间的人际关系, 同时, 班主任对这名学生的关爱之情也是真诚的, 所以这同时也 是 “交往行为”。策略性和交往性在这里是同一话语的两个 方面。

“交往性” 和 “策略性” 的冲突也体现在 “以教师为 中心的话语” 中。这一类话语不仅体现为会话行为和规范 立场行为, 更突出的体现为戏剧行为, 这在教师经验交流 会、校本研修、教师叙事等活动的话语中有明显体现, 这 类话语也有利于沟通和交往, 其话语的功能重在自我表现, 要求语言的真诚性。同时, 这类话语也可以是一种策略行 
为, 比如在职称评定会中, 为了评上职称而夸大事实夸张 感情。

同样的, “交往性” 和 “策略性” 也交织在 “以教师为 中心的话语” 中。比如在大量的 “教师叙事” 中, 明显地 体现了教师话语的真实性、正确性和真诚性。但是, 教师 叙事中的 “教师” 明显地比现实中教师的话语和行为更 “正 确”, 更 “真诚”: 通常一个曲折动人的故事背后都有一颗 热爱学生、追寻教育理想的心。到底是所有进行教育叙事 的教师都有这样一颗心, 还是在教育叙事中不得不表现出 这样的 “心”? 还是当 “爱” 与 “心” 近乎成为教师的 “意 识形态” 后的一种自我暗示的结果? 当一种心灵的审视需 要交由众人围观时, 当有一种永远 “正确” 的东西存在时, 众人恐怕便会永远看到绝对正确的心灵。

\section{2. 教师话语中 “交往性”与 “策略性” 的交织}

哈贝马斯的上述四种类型的框架主要是针对 “语言互 动” 的, 但他关于 “交往性” 和 “策略性” 的两分法却可 以有更广泛的适用范围, 因为 “交往性” 和 “策略性” 的 两分法扎根于 “交往理性” 和 “工具理性” 的对立, 而理 性几乎是人类所以行为的根基。所以不妨用这两分法审视 教师文本。

“交往性” 和 “策略性” 不仅交织在具体的教师话语 中, 尤其体现在教师文本的 “互文性” 中。福柯 (Foucault, 1972:98）认为, “不可能有什么陈述不以这种或那种方式 再次实现其他的陈述”, 这便是 “互文性”。费尔克拉夫将 互文性分为两类: “明确的” 互文性和 “建构的” 互文性, 前者指 “其他文本明显地出现在正被分析的这个文本中”; 后者指 “除了结合或是回应其他文本以外, 一个文本的互 文性还可以被看作是体现了它与习俗 (conventions) (文类, 话语, 风格, 行为种类) 的潜在的复杂关系, 它们统统被 建构起来, 以便形成一个话语秩序” (费尔克拉夫, 2003[1993]: 95), 建构的互文性关注的是某种特定文本是 以何种方式 “占用” (appropriate) 话语秩序（包括文类, 话语, 风格, 行为种类等), 即通过话语秩序要素的结合来 建构某一特定话语类型, 这种建构的互文性被费尔克拉夫 称为“话语互联性 (interdiscursivity)”, 被辛斌 (2002:15-21) 称为体裁互文性 (generic intertextuality), 并将其定义为 “语 篇中不同风格、语域或体裁特征的混合交融”。

“教案” 突出体现了明确的互文性, 大部分教师的教 案会以明确的方式再现课本和教学参考书的话语。教师书 写教案的过程, 不仅是个文本生产的过程, 更是一个文本 消费的过程。教师需要 “吃透” 课本和教学参考书, 也就 是尽可能地内化 “法定文化” 后再编写教案, 然后依照教 案与学生进行语言互动。比如, 教师在讲解一首诗歌时,
他不能够甚至不应该主要按照他的理解或感悟来备课, 他 首先需要考虑课本和教学参考书的解释, 此刻教师呈现的 是课本和教科书眼中 “真实的” 世界和 “正确的” 规范, 还必须 “真诚” 地表达法定的情感。显然, 他的讲解将是 策略性的, 这种话语实践中的 “策略性” 与其说是教师以 法定的话语为手段教育学生, 实现学生掌握法定文化获取 高分的目的, 还不如说那套法定的话语以教师为手段, 实 现对每个学生的教化。

但另一方面, 这里的话语仍然可以是一种交往行为。 如果教师完全内化了课本和教学参考书中的法定文化, 那 么他在传授时, 他会真诚地以书（这里指课本和教学参考 书）中的世界为自己的世界, 书中的情感为自己的剧本, 书中的规范为自己的准则。那时, 他将以最大的真诚扮演 自己的角色, “交往性” 和 “策略性” 无法分离。

教案体现的是明确的互文性, “教师论文” 则体现了建 构的互文性。这里的 “教师论文” 是指随着中小学科研的 兴起, 中小学教师写作的与研究相关的论文, 与专业研究 人员写作的 “科研论文” 相对应。借用费尔克拉夫 (2003) 的视角, 这种文本在 “文类 (genre)”、“话语 (discourse)” 和 “风格 (style)”等方面都杂糅了专业研究人员写作的 “科 研论文”、各级政府的 “文件” 和中小学教师写作的 “经验 总结” 等文本类型的特征。文类上至少部分具备科研论文 的形式, 话语与政府文件高度一致, 风格接近于经验总结 式的无限温情与高度认同感。“建构的互文性” 使得教师论 文往往从内容和形式呈现高度一致性, 几乎千篇一律。教 师论文作为自我反思和实践总结的产物, 有利于教师专业 发展; 但其大量发表, 似乎不是为了同行之间的交往和沟 通, 因为面貌如此一致, 几乎不需要交流和协商。那么, 一些教师论文的发表恐怕只会是达到其他目的的手段和策 略。

\section{3. 教师话语内在冲突的根源}

无论是以学生为中心的话语, 还是以教师为中心的话 语, 都体现了明显的交往性和策略性, 更为重要的是, 在 实践中两者往往交织在一起, 难以相互剥离。这两者构成 了教师话语的内在冲突。这种冲突根源何在呢?

哈贝马斯（2004[1983-1987]）认为行为的策略性源于 科技理性 (工具理性), 而交往行为与沟通理性相对应。本 文不循此社会批判的路径进行论证, 而是认为教师话语的 内部冲突根源于教育实践和教师职业的内生的矛盾。或者 更广义地讲, 与其说现代性导致了冲突, 不如说它激发、 展现和发展了实践中本来就存在的冲突。

教师借助 “以学生为中心的话语” 进行教育实践, 其 中的 “策略性” 与 “交往性” 根源于教育的 “目的性” 和 
“非目的性”。如果教育面向 “生活世界”, 教育本身只是 一种生活的样式, 一段教育就是一段生活, 生活没有高于 或外在于自身的目的, 那么教育也没有这样的目的。这样 一种教育孕育了师生的交往理性, 教师的话语就是 “交往 性” 的。可是, 教育又是有目的的, 区别往往只在于这种 目的是基于社会、个体还是文化的考量。既然教育是有目 的的, 那么教师以成功为导向的策略性行为就成了可能; 既然 “一切为了学生”, 那么 “爱” 也可以成为一种手段。

“以教师为中心的话语” 是教师发展的重要方式, 其 “策略性与 “交往性” 根源于教师职业的 “规范性” 与 “非 规范性”。“师范” 和 “normal” 的词源都显示了教师职业 的规范性; 而教师是以人育人的职业, 教师作为人的主体 性和创造性又必须得以张扬, 打破 “norm” 也是教师职业 的内在要求。“规范性” 使得教师的话语尽量符合国家和社 会的期待, 这可能导致教师运用策略对话语进行加工和包 装, 以求符合规范; “非规范性” 又使教师可能保持这类话 语的个性化和真诚性。

现实中教师话语的 “策略性” 成为了一种显在的 “危 险”。“素质教育” 和 “应试教育” 这两套主导性的教育 话语都具有强烈的目的取向, 这增强了 “以学生为中心的 话语” 的策略性的倾向。“以教师为中心的话语” 与考评机 制的结合和对竞争的强调削弱了 “以教师为中心的话语”
的 “真诚性”，甚至有从 “自我表现” 走向 “自我表扬” 的 风险。

\section{参考文献(References)}

[1] N. Fairclough, Analysing discourse:Textual analysis for social research. London: Routledge,2003.

[2] M.Foucault, The Archaeology of Knowledge. London: Tavistock Publications, 1972.

[3] N. Fairclough, Discourse and Social Change, Beijing: Huaxia Publishing House, 2003.

[4] J. Habermas, trans. by Yin Xiaorong, The Theory of Communicative Action, vol.I, Shanghai: Shanghai People's Publishing House, April 2004.

[5] Niu Haibin, trans. by Cao Weidong, Critique and Reconstruction-Education Field Research on Teacher's Discourse, Doctoral Dissertation, Changchu: Northeast Normal University, July 2010.

[6] Xin Bin," Generic Intertextuality from a Socio- Pragmatic Point of View", Foreign Language Research, vol. 24, no.2, pp.15-21, 2002. 